University of Warwick institutional repository: http://go.warwick.ac.uk/wrap This paper is made available online in accordance with publisher policies. Please scroll down to view the document itself. Please refer to the repository record for this item and our policy information available from the repository home page for further information.

To see the final version of this paper please visit the publisher's website. access to the published version may require a subscription.

Author(s): Mark Harrison

Article Title: Bombers and Bystanders in Suicide

Attacks in Israel, 2000 to 2003

Year of publication:2006

Link to published version: http://dx.doi.org/10.1080/10576100500496998

Publisher statement: None 


\title{
Bombers and Bystanders in Suicide Attacks in Israel, 2000 to 2003*
}

\author{
Mark Harrison** \\ Department of Economics \\ University of Warwick \\ Centre for Russian and East European Studies \\ University of Birmingham \\ and \\ Hoover Institution on War, Revolution, and Peace \\ Stanford University
}

\section{Abstract}

The paper analyses the results of interaction between suicide operatives and bystanders in the course of 103 suicide attacks in Israel over a recent threeyear period. It shows that bystanders' intervention tended to reduce the casualties arising by numbers that were both statistically and practically significant. When bystanders intervened, however, this was often at the cost of their own lives. The value of a challenge was particularly large for suicide missions associated with Hamas, but Hamas operations were also less likely to meet a challenge in the first place. These findings, while preliminary, may have implications for counter-terrorism. More systematic collection of statistical data relating to suicide incidents would be of benefit.

* This paper appeared in Studies in Conflict and Terrorism 29:2 (2006), pp. 187-206. I thank Jari Eloranta, Peter Law, Andrew Oswald, Jeffery Round, Jeremy Smith, and the referee for advice and comments.

** Address for correspondence: Department of Economics, University of Warwick, Coventry CV4 7AL, UK. Email: mark.harrison@warwick.ac.uk 


\title{
Bombers and Bystanders in Suicide Attacks in Israel, 2000 to 2003
}

\author{
"The main thing is to guarantee that a large number of the enemy will be \\ affected. With an explosive bag or belt, the bomber has control over \\ vision, location, and timing." \\ - Hamas leader, interviewed by Nasra Hassan, "Letter from Gaza: An \\ Arsenal of Believers," The New Yorker, 19 November 2001. \\ "Officer Yaron Zamir said Mordechai realised the man was carrying a bag \\ packed with explosives and confronted him ... She added: "We have no \\ doubt that the store owner paid with his life to save others." \\ -Incidents and Casualties Database (Herzlia, Israel: International \\ Policy Institute for Counter-Terrorism), entry for 19 June 2003.
}

It is said that suicide attacks are highly effective at killing people. The terrorists' problem is that a violent action that aims to kill creates a risk to the agent, but it is hard to make the agent safer without making the victims safer too. The solution is an agent who is willing to die in order to kill with relatively high probability. This is reflected in the casualties associated with suicide attacks. Worldwide, suicide attacks account for only 3 per cent of all the terrorist incidents that took place between 1980 and 2001, but almost half of the deaths resulting from terrorism over the same period, excluding the unusually heavy casualties of $9 / 11 .{ }^{1}$

When we study suicide attacks in more detail we find that their effectiveness is highly variable. The catastrophic scale of $9 / 11$ when four coordinated blows by 19 men killed 2,973 people is at one extreme. At the other extreme we will see that many suicide attacks injure no one but the perpetrator. In between lies a wide spectrum of variation. This suggests that the common perception that suicide attacks invariably result in widespread death and injury reflects a selection bias: we are more likely to note the attacks that succeeded than the ones that failed.

We will see that the suicide attack is a rather fragile method of causing death and injury. The high variability in the outcomes of suicide attacks raises an interesting problem: what factors make the difference between success and failure? Is it chance, or do observable factors account for these differences? If such factors exist, who controls them: the attacker, the defenders, or the potential victims?

The events of $9 / 11$ draw attention to the varying roles of the bystanders who were intended to die. Four distinct but coordinated blows resulted in many civilian deaths. In one case, that of United Airlines Flight 93, the passengers took a hand; once they understood the threat they responded to it 
by organizing themselves to attack the hijackers. ${ }^{2}$ Their intervention took away the hijackers' initiative; it did not save them because it precipitated the destruction of the aircraft and of themselves, but the hijackers never reached their intended target in Washington and hundreds of additional deaths were probably averted. In this case, therefore, intervention appears to have carried a large negative residual in the number of casualties per incident.

This suggests that the effects of citizens' responses to suicide operations that are already in progress deserve closer study: it would be of interest to know whether a similar effect could be found in a larger sample. Such questions can, of course, also be tackled by more direct means, for example by studying participant and witness perceptions gathered through interview and examination. The use of statistics is complementary to these methods since it offers the possibility of confirming or rejecting opinions formed on the basis of personal observation or particular cases.

The context for this study is provided by two literatures. One literature deals with the rational purposes underlying suicide attacks. To carry out a suicide attack requires a large number of agents, each looking for different payoffs, to coordinate their actions in a common enterprise. The payoffs that arise from a successful operation may be defined in strategic, tactical, and reputational gains of organizations and persons and computed by changes in their political, social, and moral capital. ${ }^{3}$ In this sense the casualties associated with terrorist attacks are unimportant in themselves; they are always means to some other end. At the same time this should not lead us to underplay their significance, since without the casualties the purposes of those responsible for them would not be achieved. Suicide attacks not only kill people but are designed to do so. When they fail to kill, they also fail in their wider purposes. Correspondingly, if the underlying purpose of counter-terrorism is to defeat terrorism, one of its intermediate goals must be to safeguard the intended victims.

A second literature of relevance is that concerned with citizen response to natural and technological disasters. Longstanding findings of empirical research show that, in the acute phase of such emergencies, bystanders may experience fear, commonly rationalized as "panic," but despite this they remain fully capable of purposeful action. They use the available information to guide their actions, and act to reduce danger to themselves and others. They are not demoralized or reduced to aimless panic or wild flight; only under very specific conditions do they try to save themselves at the expense of others or cease to respect the lives and property of others. ${ }^{4}$ On the contrary, community-oriented or altruistic behaviour may become widespread and persist for days, weeks, or months. ${ }^{5}$ Opportunities to extend these lines of research to situations arising from terrorism have been limited, however. Much government planning for emergencies generally, and specifically for terrorist operations, continues to be driven by expectations that citizens will display passivity or helplessness in the face of emergencies and, if provided with full information about current threats, will use it in irrational or antisocial ways. ${ }^{6}$ Empirical study of citizens' behaviour when under attack by terrorists can thus widen our knowledge of citizen responses to emergencies and also further inform government plans to manage terrorist threats.

In the present paper I will look at the intervention of bystanders in 103 suicide attacks that took place in Israel between November 2000 and 
November 2003. The pattern of outcomes of Palestinian terrorist attacks has received some attention recently but discussion has been largely confined to descriptive measures of trend and composition. ${ }^{7}$ There is scope for closer analysis. What is the extent of variation in the immediate outcomes of suicide attacks, measured by the number of casualties, and what are the main sources of variation that we can measure? We will find a relatively small number of operations with high yield measured by the number of casualties, and a much larger number with a relatively low yield. What factors contribute most to explaining the low-yielding outcomes, and where does citizen response figure among them?

A significant effect of bystander intervention would have practical implications for counter-terrorism policies and the management of terrorist threats. Standard assessments of the scope for counter-measures distinguish three phases: prevention, absorption, and reconstruction. ${ }^{8}$ It may be that, between prevention and absorption, we should identify another distinct stage in which intervention can significantly affect outcomes: that of the attack when it is actually in progress.

The present paper makes a first pass at these problems. First it gives a simple account of what we will call the "technology" of violence. Then, it describes the general patterns in the data. In this context, it goes on to deal specifically with the descriptive statistics relating to bystander intervention. Finally, it engages in some simple multivariate analysis.

\section{The Technology of Violence}

What makes the outcomes of suicide attacks vary? The number of victims $V$ arising from the $i$ th incident in a series can be thought of as depending on the size of the locally vulnerable population $N$ multiplied by a probability $p$ that each will be victimized, plus a random error $u$, so $V_{i}=p_{i} \cdot N_{i}+u_{i}$.

The number at risk, $N$, is essentially a matter of the place and time of the attack, such as a military checkpoint, an open-air market, or a crowded building. It might be affected by the history of previous attacks; unanticipated changes in the location of attacks, for example, are likely to cause potential victims to alter their behaviour by avoiding places of increased risk, so reducing the vulnerable population.

The probability $p$ of victimization depends on the technology of the suicide operation, broadly defined. Technology embraces the techniques by which the faction recruits, screens, motivates, and commits the attacker psychologically; the techniques for concealment that allow the attacker to infiltrate the target location; the technical device, for example a car bomb or an explosive belt; and the personal qualities of the attacker that bear upon the will and ability to execute the attack.

An important aspect of technology in this broad sense is operational knowhow, which is of two kinds, explicit and tacit. The explicit part of the knowledge required to organise a suicide mission can be acquired through passive study and does not rely on organization. Acquisition of the tacit component requires individuals to engage in learning-by-doing and relies on an organization to store and share the lessons of experience; Robert Pape notes that this is one objective of al-Qaeda. ${ }^{9}$ The importance of tacit knowledge helps to explain why there is almost always an organization involved; suicide 
attacks are rarely if ever mounted spontaneously by individuals. For present purposes, therefore, the technology of a given suicide operation comprises not only the techniques used directly to mount the attack but also the common knowledge available from all previous suicide operations, and the private knowledge that the faction has built up for itself from its own previous operations.

Finally, a given technology has given scope for disruption. An operation can fail because of bad luck, because the operative's motivation can fail, or because of intentional counter-action by adversaries or intended victims.

In short, when an attack takes place, some people will be there and will be at risk. The risk they face depends first and foremost on the technology of the operation. There is a set of things that the faction tries to control: "vision, location, and timing." But in a given place and time the given technology can be disrupted. The faction chooses the technology, but the bystanders can also choose to intervene; if they do so, it may affect the outcome. Finally, luck will take a hand. The statistics will let us weigh these factors and set the role of citizen response in context.

\section{What the Data Show}

The International Policy Institute for Counter-Terrorism, Herzlia, Israel, provides a searchable on-line database of terrorist actions in the Arab-Israeli conflict, with details of terrorist attacks in Israel since September $2000 .{ }^{10}$ The incidents are characterized by the date and place of the attack; the type of attack, e.g. a suicide operation; the character of the target and device employed; the organizational affiliation of the attacker, and the number of victims killed and injured. There is a brief textual description of the incident. The individual casualties are given personal attributes such as name, age, sex, nationality, and religion, often accompanied by brief biographical details and a note, not in standard form, of any role they may have played in the incident. ${ }^{11}$

For present purposes the data are drawn from a three-year period beginning on 6 November 2000, when the first suicide operation included in the database is reported, and finishing on 3 November $2003 .{ }^{12}$ I curtail the sample then because the frequency of incidents was falling sharply at that point. After a long period in which every month had seen two or more attacks, more than six weeks passed between the last attack in the sample and the next, on 22 December 2003. There was one in January 2004 and none in February before a new cluster in March. The reason for the change in pattern was the new situation arising from the approaching completion of Israel's security fence and the turn to assassination of Palestinian faction leaders. ${ }^{13}$ Over this period the database reports 103 suicide attacks which, coded numerically, yield the figures shown in Table 1. 
Table 1. Suicide Attacks, November 2000 to November 2003: Observed Characteristics

\begin{tabular}{|c|c|c|}
\hline Incidents, to & otal number & 103 \\
\hline Victims, to & tal number & 3516 \\
\hline \multirow[t]{2}{*}{ Of which, } & Deaths & 440 \\
\hline & Injuries & 3076 \\
\hline \multicolumn{2}{|c|}{ Casualties per incident } & 34.1 \\
\hline \multicolumn{2}{|c|}{ Attackers, total number } & 112 \\
\hline \multirow[t]{3}{*}{ Of which, } & Male & 100 \\
\hline & Female & 7 \\
\hline & \multicolumn{2}{|c|}{ Not known } \\
\hline \multicolumn{2}{|c|}{ Casualties per attacker (“adjusted” casualties) } & 31.4 \\
\hline \multicolumn{2}{|c|}{ Average age of attacker, years } & 21.7 \\
\hline \multicolumn{2}{|c|}{ Age not known, number of attackers } & 15 \\
\hline \multicolumn{3}{|c|}{ Attack employed: } \\
\hline \multicolumn{2}{|c|}{ Personal device } & 87 \\
\hline \multicolumn{2}{|c|}{ Car } & 14 \\
\hline \multicolumn{2}{|l|}{ Boat } & 2 \\
\hline \multicolumn{3}{|c|}{ Attack was aimed at: } \\
\hline \multicolumn{2}{|c|}{ Civilian target } & 76 \\
\hline \multicolumn{2}{|c|}{ Military target } & 10 \\
\hline \multicolumn{2}{|l|}{ Uncertain } & 17 \\
\hline \multicolumn{3}{|c|}{ Attack was sponsored by: } \\
\hline \multicolumn{2}{|l|}{ Hamas } & 44 \\
\hline \multicolumn{2}{|c|}{ Martyrs of al-Aqsa Brigade } & 26 \\
\hline \multicolumn{2}{|c|}{ Palestinian Islamic Jihad } & 24 \\
\hline \multicolumn{2}{|c|}{ Other or not known } & 9 \\
\hline \multicolumn{2}{|c|}{ Attack was prevented } & 2 \\
\hline \multicolumn{3}{|c|}{ Attack took place in or at: } \\
\hline \multicolumn{2}{|l|}{ Street } & 32 \\
\hline \multicolumn{2}{|c|}{ Checkpoint } & 16 \\
\hline \multicolumn{2}{|c|}{ Travel Stop } & 15 \\
\hline \multicolumn{2}{|l|}{ Bus } & 14 \\
\hline \multicolumn{2}{|l|}{ Café } & 14 \\
\hline \multicolumn{2}{|l|}{ Store } & 7 \\
\hline \multicolumn{2}{|l|}{ Offshore } & 2 \\
\hline Residence & & 1 \\
\hline Attacker w: & as challenged & 40 \\
\hline
\end{tabular}

Note. "Personal device" was a bag, belt, or vest carried on the attacker's person.

\subsection{How Effective are Suicide Attacks?}

On average each incident recorded in this dataset caused 4.3 deaths and 29.9 injuries, making 34.1 for the total of victims of an average incident. The number of deaths is therefore below the worldwide average of 13 per incident for suicide attacks over the period from 1980 to 2001, excluding 9/11, but above the average of less than one per incident for all kinds of terrorism over that period. ${ }^{14}$

The attacks that we are looking at were highly variable in effectiveness: just 15 attacks caused half of the more than 3,500 combined deaths and 
injuries, while 22 killed nobody but the perpetrator. The incidents may be ranked in increasing order of the number of casualties (deaths plus injuries). Figure 1 charts the cumulative percentage of casualties against the cumulative percentage of incidents. It is a Lorenz curve of the kind often used to measure inequality. If all attacks were equally effective, the result would be a diagonally rising straight line. In fact the relationship is highly curved and this reflects the variation in effectiveness.

Figure 1. Casualties and Incidents: Cumulative, Per Cent of Totals

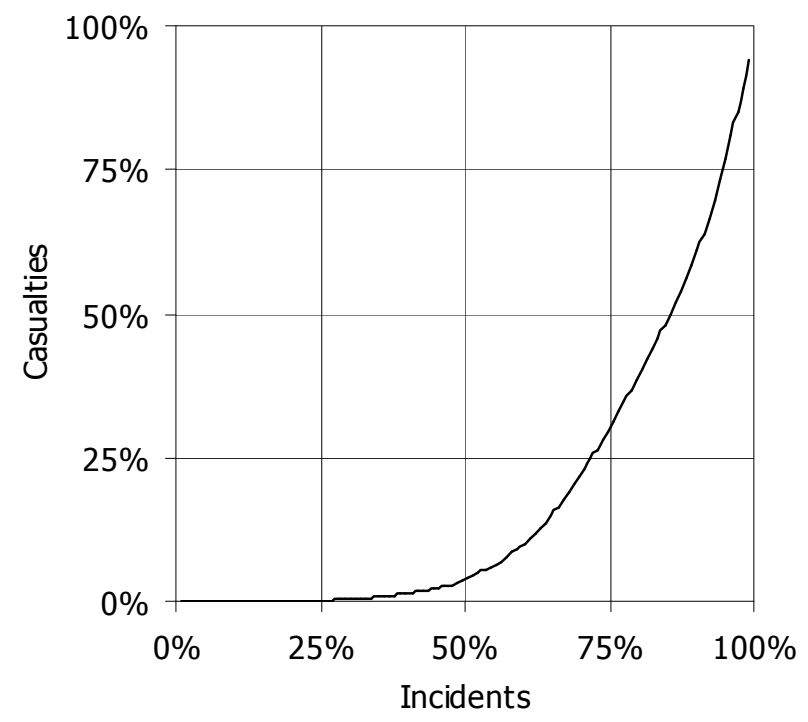

The sample is confined to operations that reached the final stage of execution and excludes a much larger number that were abandoned or disrupted by the security forces at a preparatory stage. According to statistics published by the Israeli Ministry of Defence, no attacks were intercepted in the last four months of 2000 but the number rose to 21 intercepted in 2001, and 112 and 179 in 2002 and the first eleven months of 2003 respectively, making 312 in total. ${ }^{15}$ Over the same period the ICT database shows 103 attacks, 101 of which were carried through in some form. Including the attacks that were abandoned or intercepted, failed attacks appear to have outnumbered attacks that were executed by three to one. These are absent from the distribution that we analyse below, since we lack knowledge of the statistical correlates of the incidents that did not happen.

\subsection{Single Operatives and Accomplices}

The suicide attackers responsible for the incidents recorded in the dataset did not work alone. Each was recruited and motivated by a factional organization, and supported logistically by two or three aides in a "martyrdom cell." ${ }^{16}$ At the moment of execution, however, most were left alone with their victims.

In nine incidents, however, two assailants coordinated their actions. Working together, did two achieve more or less than they would have done separately? At first sight returns were diminishing. If the number of casualties is divided by the number of attackers, then "adjusted casualties" are 31.4 per perpetrator, somewhat less than the average of 34.1 per incident. The average number of victims of two assailants working together was 47.6 compared with 
32.9 for one: in other words doubling the number of operatives did not double the number of casualties but increased it by about half.

\subsection{Attackers' Age and Sex}

Age is reported for 98 of the 112 attackers. The average was 21.7 years. There was limited variation around this figure: the youngest was 16 and the oldest 48 , but 88 of the 98 were aged between 17 and 26 . As a result there was no significant relationship between the number of victims of a suicide attack and the age of the attacker.

Only a few attackers, 7 out of 112, were women. Of the remainder 92 were known to be male, leaving 4 for whom sex is not reported; one supposes that these too are likely to have been men. The female attackers are surprisingly few given the intense publicization of their role in the media. In all cases they completed their operations alone. Their involvement in an operation was associated with a large increase in the number of casualties. The average number of victims of an attack by a woman was 60.4 , compared with 33.6 when the assailant was male.

The data do not capture other personal qualities that are likely to have influenced the operational effectiveness of the attacker, for example personal maturity, appearance, the education and training required to execute complex tasks, experience of Israeli society, and fluency in Hebrew. ${ }^{17}$ Nor do we learn anything about their immediate logistical support.

\subsection{Devices}

In most incidents, 87 out of 103, the attacker's weapon of choice was a bag, belt, or vest laden with explosives and carried on their person. In 14 cases a car bomb was used, and in two cases explosive were loaded onto a boat. The number of casualties that resulted varied strongly. The average number of casualties in an incident involving an attacker using a personal device was 38.7 , compared with 10.2 victims of the average car bomb and only 2.0 where a boat was used. These differences arose partly because the choices between alternative devices were to some extent linked to other choices, between military versus civilian targets and between available locations for an attack.

\subsection{Military Versus Civilian Targets}

The majority of attacks, 76 out of 103, were clearly aimed at civilian targets. In 10 cases the intended target appears to have been armed security personnel; for example an attacker deliberately detonated explosives beside a military vehicle or a police station. In the remaining 17 cases the intended target was unclear, usually because the attack was triggered by a security operation, or the operation was interrupted or prevented. In most of the "uncertain" cases the security forces took the force of the attack but may not have been the intended victims and in some cases their assessment after the event was that the attacker had been en route to some other intended target.

Not surprisingly, the figures suggest that civilians provided a "softer," more vulnerable target. The average number of casualties of attacks clearly aimed at civilians was 45.9, compared with 1.8 casualties in attacks aimed at military or armed security personnel, and 0.6 casualties in those attacks that could not be classified. 


\subsection{Location of Attacks}

The outcome of an attack varied strongly with its location. Each incident is classified according to whether it occurred in the street or a bus, at a bus stop or train station, in a store or café, or at a checkpoint or roadblock. Two incidents occurred offshore when terrorists directed a boat loaded with explosives against a naval vessel. One occurred when an attacker broke into a settler's home. Finally, two attacks were physically prevented and thus did not take place anywhere.

Table 2. Location: Incidents and Casualties

\begin{tabular}{lrr}
\hline & $\begin{array}{r}\text { Number of } \\
\text { incidents }\end{array}$ & $\begin{array}{r}\text { Casualties } \\
\text { per incident }\end{array}$ \\
\hline Attack was prevented & 2 & 0.0 \\
Attack took place in or at: & & \\
Café & 14 & 68.3 \\
Bus & 14 & 50.5 \\
Travel stop & 15 & 41.3 \\
Street & 32 & 31.2 \\
Store & 7 & 30.3 \\
Offshore & 2 & 2.0 \\
Checkpoint & 16 & 1.2 \\
Residence & 1 & 1.0 \\
All incidents & 103 & 34.1 \\
\hline
\end{tabular}

Table 2 shows that the most favoured location was the street and the average street incident resulted in 31.2 casualties. The deadliest location, however, was cafés and restaurants, where 14 attacks averaged 68.3 casualties. The table ranks locations in descending order of the casualties associated with an attack on each. At the lower extreme, 14 attacks on checkpoints yielded only 1.2 casualties on average. Not surprisingly, a condition for high casualties was the gathering of people in a street market or shopping mall, or in a queue for public transport; casualties were increased where the explosion was contained within a structure such as a bus or a building.

\subsection{Factions}

Three factions carried out the great majority of the 103 operations. Table 1 showed that 94 attacks were carried out by just three organizations: Hamas (the Islamic Resistance Movement), the Martyrs of al-Aqsa Brigade (the terrorist wing of Fatah), and Palestinian Islamic Jihad. Of the others two were carried out by Fatah itself, one by Fatah Tanzim, and one by the Popular Front for the Liberation of Palestine. Five are unattributed; this could mean either that no organization was involved or, more likely, that the organization involved was not reported.

Table 3 shows that there was considerable variation in the casualties associated with incidents sponsored by the different organizations. Hamas, which mounted 43 per cent of the attacks, was responsible for 56 per cent of the injuries and 69 per cent of the deaths. The proportion of deaths in total casualties, therefore, was also higher for Hamas attacks than for others. On average, each Hamas operation resulted in 46.1 casualties compared with 28.7 
casualties when the Martyrs of al-Aqsa Brigade claimed responsibility and 22.8 when the attack was attributed to Palestinian Islamic Jihad.

Table 3. The Factions: Incidents and Casualties

\begin{tabular}{|c|c|c|c|c|c|}
\hline & $\begin{array}{l}\frac{\tilde{U}}{0} \\
\frac{0}{0} \\
\Xi \\
\bar{Z}\end{array}$ & $\begin{array}{l}\stackrel{\Xi}{\Xi} \\
\stackrel{\Xi}{\Xi} \\
\text { İ }\end{array}$ & 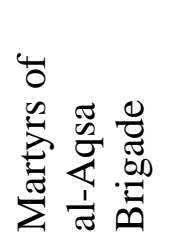 & 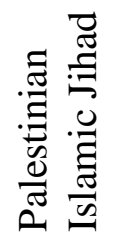 & 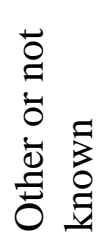 \\
\hline \multicolumn{6}{|l|}{ Totals of: } \\
\hline Incidents & 103 & 44 & 26 & 24 & 9 \\
\hline Deaths & 440 & 302 & 70 & 59 & 9 \\
\hline Injuries & 3076 & 1725 & 676 & 487 & 188 \\
\hline Casualties & 3516 & 2027 & 746 & 546 & 197 \\
\hline \multicolumn{6}{|l|}{ Per cent of row totals: } \\
\hline Incidents & 100 & 43 & 25 & 23 & 9 \\
\hline Deaths & 100 & 69 & 16 & 13 & 2 \\
\hline Injuries & 100 & 56 & 22 & 16 & 6 \\
\hline Casualties & 100 & 58 & 21 & 16 & 6 \\
\hline Deaths, per cent of casualties & 13 & 15 & 9 & 11 & 5 \\
\hline Casualties per incident & 34.1 & 46.1 & 28.7 & 22.8 & 21.9 \\
\hline
\end{tabular}

Some of the difference in outcomes can be associated with variations in the distinct modus operandi that each organization developed. But most of the operational differences that we can observe are not large. Table 4 shows that the factions overwhelmingly recruited young men. Hamas did not recruit women at all over the period covered, sponsoring an attack by a female suicide operative for the first time on 18 January 2004. The factions shared similar preferences for a "personal device" (a bag, belt, or vest) and for a civilian target. Hardly any attacks in the dataset were prevented. There were a few differences in the locations associated with the attacks mounted by each faction; Hamas appears to have become master of the bus bombing. Generally, at least three quarters of the operations mounted by each of the factions succeeded in reaching targets of higher or intermediate average value, but not all then realized the value that was average for the target.

The largest visible difference among the factions was in the rate of challenge to which their operations were liable. Less than one quarter of attacks by Hamas were challenged compared with half or more of those mounted by the Martyrs of al-Aqsa Brigade or Palestinian Islamic Jihad. I discuss this further in the next section.

The data confirm that Hamas had a more effective technology, or organizational modus operandi, for suicide operations. In general, modus operandi reflects both collective qualities of the organization and qualities of the individuals that the organization employs. We will consider these briefly. 


\begin{tabular}{|c|c|c|c|c|c|}
\hline & 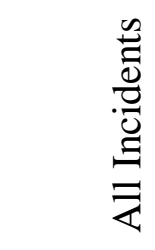 & 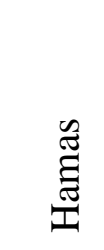 & 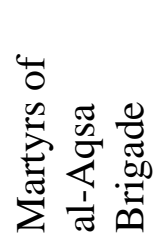 & 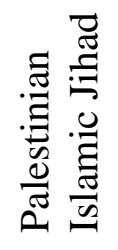 & 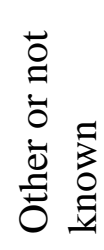 \\
\hline Incidents, total number & 103 & 44 & 26 & 24 & 9 \\
\hline Attackers & 112 & 46 & 28 & 28 & 10 \\
\hline \multicolumn{6}{|l|}{ Of which, females, where } \\
\hline known & 7 & 0 & 3 & 3 & 1 \\
\hline $\begin{array}{l}\text { Average age of attacker, } \\
\text { where known, years }\end{array}$ & 21.7 & 22.8 & 19.0 & 23.0 & 21.9 \\
\hline \multicolumn{6}{|c|}{ Per cent of incidents: } \\
\hline \multicolumn{6}{|l|}{ Device: } \\
\hline Personal device & 84 & 86 & 85 & 79 & 89 \\
\hline Car & 14 & 11 & 15 & 17 & 11 \\
\hline Boat & 2 & 2 & 0 & 4 & 0 \\
\hline Total & 100 & 100 & 100 & 100 & 100 \\
\hline \multicolumn{6}{|l|}{ Target: } \\
\hline Civilian target & 74 & 77 & 69 & 79 & 56 \\
\hline Military target & 10 & 14 & 4 & 4 & 22 \\
\hline Uncertain & 17 & 9 & 27 & 17 & 22 \\
\hline Total & 100 & 100 & 100 & 100 & 100 \\
\hline Attack was prevented & 2 & 2 & 0 & 4 & 0 \\
\hline \multicolumn{6}{|l|}{ Attack took place at or in: } \\
\hline Café & 14 & 16 & 12 & 17 & 0 \\
\hline Bus & 14 & 25 & 0 & 13 & 0 \\
\hline Travel Stop & 15 & 18 & 12 & 17 & 0 \\
\hline Street & 31 & 20 & 38 & 29 & 67 \\
\hline Store & 7 & 2 & 15 & 4 & 11 \\
\hline Offshore & 2 & 2 & 0 & 4 & 0 \\
\hline Checkpoint & 16 & 14 & 23 & 8 & 22 \\
\hline Residence & 1 & 0 & 0 & 4 & 0 \\
\hline Total & 100 & 100 & 100 & 100 & 100 \\
\hline Attacker was challenged & 39 & 23 & 58 & 50 & 33 \\
\hline
\end{tabular}

A collective attribute of possible significance is experience shared through teamwork. Did organized learning-by-doing raise the effectiveness of some attacks above others? The first and last rows of Table 3 could be read in such as way as to support this hypothesis: thus Palestinian Islamic Jihad, responsible for only 24 operations, achieved only 22.8 casualties per operation; the Martyrs of al-Aqsa Brigades mounted 26 operations that yielded 28.7 casualties on average; Hamas, which mounted the largest number of operations, 44, achieved the highest average casualties of 46.1 per operation. But the learning-by-doing hypothesis fails a more discriminating test. If learning was at work we should expect clear upward trends over time in the casualties per incident that each faction mounted. This is not the case; the time trends of casualties achieved by each faction were approximately flat over the period studied. ${ }^{18}$ Thus it seems not to have been the case that the factions 
gradually learned from experience to select more effective operatives or devices, or higher-value targets, or to control disruption more effectively; if experience was a factor, it was wholly acquired before November $2000 .^{19}$

Evidence of learning by the factions may be obscured if their adversaries were learning contemporaneously. During this period Israeli society and its security forces were also working out how to disrupt suicide operations. The evidence of the Israeli defense ministry, already cited, showed a rising trend in the number of intercepted attacks over the period. The present dataset provides some support for this view: 27 per cent of attacks were challenged in the period from November 2000 to December 2001, but the rate of challenge rose to 45 per cent in 2002. It then levelled off, standing at 42 per cent in 2003.

Individual-level factors that could have contributed to differences in factional outcomes do not emerge directly from the data, which provide little information about the qualities of attackers other than age and sex. An obvious possibility, though, is that Hamas mounted more effective operations because it was able to attract volunteers of higher average quality or could select for higher quality because its volunteers were more numerous relative to the vacancies. Its relative success in operations is most simply explained if Hamas operatives had superior education and experience and this gave them a "passport" to move more freely into and through Israeli society.

Eli Berman and David D. Laitin suggest that Hamas secured an advantage vis à vis the other factions by positioning itself at the fundamentalist end of the market for terrorists; this allowed it to recruit from the more committed, more qualified segment of the distribution of volunteers. In this way Hamas made itself a "strong" club with an enhanced propensity for more and deadlier suicide attacks. ${ }^{20}$ We see that, despite being the more efficient operator, Hamas did not take over the other factions or drive them out of the political market place. The others exploited greater theological flexibility to compensate for an inferior modus operandi by employing women, for example, a tactic that Hamas did not allow itself to copy until the end of 2003. Thus, the logic of organizational rivalry allowed practices of varying efficiency to persist side by side.

\section{Bystanders' Intervention}

In a high proportion of incidents, 40 out of 103, one or more of those affected were not passively victimized but are reported to have intervened in the process of the attack and potentially influenced its outcome. ${ }^{21}$

Intervention took several forms. Civilian witnesses or security personnel became suspicious and intervened to challenge or restrain an attacker, or called the security forces. Security personnel challenged attackers by acting on suspicion or information. Routine security measures at checkpoints or roadblocks sometimes uncovered terrorists who may have been en route to other targets, or intended specifically to target military personnel at the checkpoint concerned, or had formed the intention simply to proceed until challenged. Table 5 shows that of the 16 incidents at checkpoints or roadblocks 9 were triggered by challenges, but this also means that most challenges took place in other contexts; the largest number of challenges took place in the street.

The result of a challenge was almost always to trigger the attack; only in two cases was an attack actually prevented. On the other hand a challenge is 
likely to have had the effect that the attacker lost the initiative and became unable to choose the time and place of the attack.

While the person who intervened often became a victim it was sometimes claimed that many lives were saved as a result. Thus a security guard was killed preventing an attacker from entering a Jerusalem café on 8 September 2003. Afterwards his brother said: "I'm sure he knew he was stopping a terrorist. He saved at least 30 lives." This repeated a similar incident at the entrance to a shopping mall in Afula on 19 May when two security guards saved "countless lives"; one was killed and the other severely injured. On 19 June 2003 an Israeli shopkeeper confronted a young man who had entered his store carrying explosives; the police concluded that the intended target was a nearby bus stop and stated: "We have no doubt that the store owner paid with his life to save others." On 4 October a restaurant security guard also "paid with his life in order to protect others, whether they were Arabs or Jews. We are all brothers in this country" (his own brother's words).

The statistics lend support to this hypothesis. Table 5, col. 6, shows that in every class of location a challenge tended to reduce the number of casualties associated with an attack: either the challengers took the force of the explosion or some of the bystanders were given time to save themselves. Overall, the average number of casualties in an incident that was interrupted by bystanders was 16.9, compared with 45.1 when the attacker was allowed to carry out the operation without distraction, a difference of 28.2 victims.

Table 5. Bystanders' Intervention: Incidents, Casualties, and Location

\begin{tabular}{|c|c|c|c|c|c|c|}
\hline & $\begin{array}{r}\text { Num } \\
\text { inciden } \\
\text { attacke }\end{array}$ & $\begin{array}{l}\text { of } \\
\text { here } \\
\text { as: }\end{array}$ & \multirow{2}{*}{ 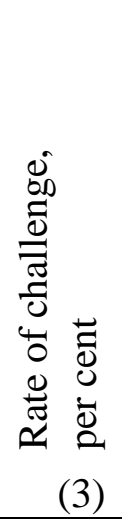 } & \multicolumn{2}{|c|}{$\begin{array}{l}\text { Number of } \\
\text { casualties per } \\
\text { incident where } \\
\text { attacker was: }\end{array}$} & \multirow{2}{*}{ 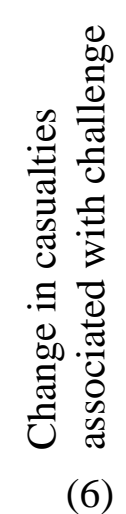 } \\
\hline & 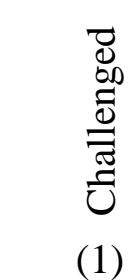 & 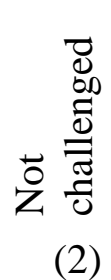 & & 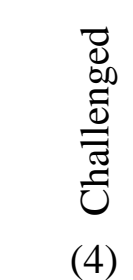 & 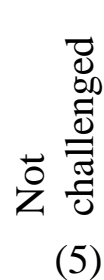 & \\
\hline $\begin{array}{l}\text { Attack was } \\
\text { prevented } \\
\text { Attack took } \\
\text { place in or at: }\end{array}$ & 2 & 0 & 100 & 0.0 & $\ldots$ & \\
\hline Café & 3 & 11 & 21 & 53.0 & 72.5 & -19.5 \\
\hline Bus & 3 & 11 & 21 & 19.0 & 59.1 & -40.1 \\
\hline Travel stop & 7 & 8 & 47 & 39.9 & 42.5 & -2.6 \\
\hline Street & 13 & 19 & 41 & 12.8 & 43.8 & -31.0 \\
\hline Store & 2 & 5 & 29 & 0.5 & 42.2 & -41.7 \\
\hline Offshore & 1 & 1 & 50 & 4.0 & ․ & \\
\hline Checkpoint & 9 & 7 & 56 & 1.1 & 1.3 & -0.2 \\
\hline Residence & 0 & 1 & 0 & & 1.0 & \\
\hline All incidents & 40 & 63 & 39 & 16.9 & 45.1 & -28.2 \\
\hline
\end{tabular}

The arithmetic of Table 5 may understate the true difference made by interventions. At first sight many challenges saved few lives; those at 
checkpoints, for example, resulted in hardly any saving of casualties. This assumes, however, that the general pattern of attacks would have remained unchanged in the absence of interventions. Possibly, however, challenges in low-value locations prevented attackers from proceeding to higher-value targets. If the targets in Israeli society were arrayed in order of diminishing value, based on Table 2, they would form steps on a ladder:

\begin{tabular}{||c||}
\hline Café \\
\hline \hline Bus \\
\hline \hline Bus stop \\
\hline Store \\
\hline Street \\
\hline Checkpoint
\end{tabular}

The higher-value targets at the top of the ladder were cafés and buses; intermediate targets were commuter queues and shoppers in crowded streets and stores. Checkpoints, along with private homes and naval facilities, were targets of lower value. Think of the typical attacker as setting out to climb this ladder: to reach a café she had to pass a checkpoint, walk along a street, enter and leave a store, wait for a bus, and travel on it to the destination. At each step the attacker was screened by the watchful eyes of soldiers, security guards, shoppers, and commuters. By passing each step without challenge she gained access to a target of higher value. If challenged at any stage, she ended the game in sudden death. If this is the right analogy, then the effectiveness of screening is measured not just by the victims saved at each step but also by those saved because some attackers were challenged before they could reach targets of higher value.

What factors favoured intervention? It is sometimes suggested that women have been used in suicide attacks because they are less likely to be challenged than men. The data do not support this view, although the number of observations is small. Of the seven female attackers in the dataset four were challenged; thus women were challenged with higher frequency than men. Only one was challenged at a checkpoint, however.

Table 6 shows that the identity of the sponsoring faction was also an important influence. Less than one quarter of Hamas operations encountered a challenge compared with more than half of all other operations. This is not because Hamas operations were biased towards locations where challenges were less likely to be mounted. Hamas operatives were less likely to be challenged in any given location, including checkpoints. 
Table 6. Bystanders' Intervention in Hamas Operations: Incidents, Casualties per Incident, and Location

\begin{tabular}{|c|c|c|c|c|c|}
\hline & \multicolumn{2}{|c|}{$\begin{array}{l}\text { Number of Hamas } \\
\text { operations where } \\
\text { attacker was: }\end{array}$} & \multicolumn{2}{|c|}{$\begin{array}{c}\text { Rate of } \\
\text { challenge, } \% \text { of } \\
\text { operations: }\end{array}$} & \multirow{3}{*}{ 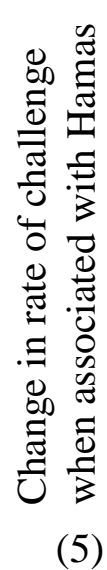 } \\
\hline & 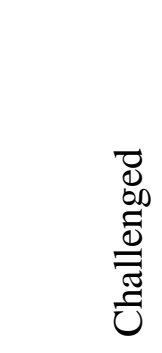 & 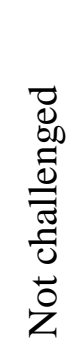 & 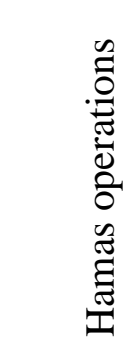 & 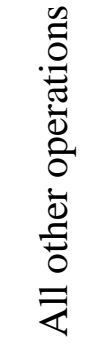 & \\
\hline & (1) & (2) & (3) & (4) & \\
\hline $\begin{array}{l}\text { Attack was } \\
\text { prevented }\end{array}$ & 1 & 0 & 100 & 100 & 0 \\
\hline $\begin{array}{l}\text { Attack took } \\
\text { place in or at: }\end{array}$ & & & & & \\
\hline Café & 1 & 6 & 14 & 29 & -14 \\
\hline Bus & 1 & 10 & 9 & 67 & -58 \\
\hline Travel stop & 3 & 5 & 38 & 57 & -20 \\
\hline Street & 2 & 7 & 22 & 48 & -26 \\
\hline Store & 0 & 1 & 0 & 33 & -33 \\
\hline Offshore & 0 & 1 & 0 & 100 & -100 \\
\hline Checkpoint & 2 & 4 & 33 & 70 & -37 \\
\hline Residence & 0 & 0 & $\ldots$ & 0 & ... \\
\hline All incidents & 10 & 34 & 23 & 51 & -28 \\
\hline
\end{tabular}

Note. Column (3) is col. (1) divided by the sum of cols (1) and (2). Col. (4) is the same for all other incidents, obtained by subtracting figures for Hamas operations in this table from the figures for all incidents shown in Table 5. Col. (5) is col. (3), less col. (4).

The actions of citizens who intervened in suicide operations that were already under way appear to deserve special note. As studies of citizen response in other emergency settings would lead us to expect, those caught up in suicide attacks may take purposeful action to reduce the threat to others. Tragically, however, this response is likely to increase the danger to themselves since the attack is often precipitated as a result.

\section{Multivariate Analysis}

Controlling for variation in other independent variables can shed more light on the roles of the attacker, the faction, and the bystanders in generating casualties. For this I estimate several regression models using ordinary least squares. As before, the number of victims $V$ arising from the $i$ th incident in a series depends on the size of the locally vulnerable population $N$ multiplied by a probability $p$ that each will be victimized, plus a random error $u$, so $V_{i}=p_{i} \cdot N_{i}+u_{i}$. Then $N$ comprises a set of target attributes including whether the target personnel were civilian or military and their location; $p$ is set by the attributes of the technology including the qualities of the attacker, the device, 
the sponsoring faction, and their susceptibility to bystander intervention. The dependent and independent variables are detailed below.

Dependent Variable

Victims The number of casualties reported as killed and injured in an incident.

\section{Independent Variables: Target Attributes}

The following variable stands for the status of the population attacked.

Civilian Equals 1 when civilians were the target and 0 when military personnel were attacked or the intended target was uncertain.

The following variables characterise Location and are mutually exclusive. The default location is the street; this includes a number of cases where the attacker was prevented from entering a café or store.

Bus Equals 1 for an attack inside a bus and 0 otherwise.

Café Equals 1 for an attack inside a café or restaurant and 0 otherwise.

Checkpoint Equals 1 for an attack at a checkpoint or roadblock and 0 otherwise.

Offshore Equals 1 for an attack offshore and 0 otherwise.

Residence Equals 1 for an attack inside a private residence and 0 otherwise.

Store Equals 1 for an attack inside a store and 0 otherwise.

Travel Stop Equals 1 for an attack at a bus stop or train station and 0 otherwise. Includes some cases where the attacker was preventing from entering a bus.

\section{Independent Variables: Technology}

The following variables characterise the technology employed in the operation, including the qualities of the operative, the device, the sponsoring organization, and the realized scope for intervention

Female Equals 1 when the attacker was reported as female and 0 otherwise.

Second Equals 1 when there were two attackers and 0 otherwise.

I do not consider the attacker's age given the number of missing observations and the lack of variation in the ages that are observed.

Vehicle Equals 1 when the bomb was conveyed by a car or boat, and 0 when it was carried about the person in a bag, belt, or vest.

Hamas Equals 1 when the faction was Hamas and 0 when the faction was the Martyrs of al-Aqsa Brigade, Palestinian Islamic Jihad, or another faction.

Challenge Equals 1 when the attack was interrupted or precipitated by a challenge and 0 otherwise.

Some restrictions on the testing procedure arise from the presence of weak multicollinearity among supposedly independent variables. I use a correlation 
matrix (not reported) and a severe test $(\mathrm{R}>0.5)$. There is little to worry about in general but enough covariation of Civilian with Vehicle, Checkpoint, and Offshore to invite caution. Offshore targets were always military and were always approached by boat. Car or truck bombs tended to be used against military targets; checkpoints were always staffed by security personnel. On this reasoning I test the influence of the locational variables and Device in one regression model and that of Civilian in another. In Table 7, Models 1 and 2 test the relationship:

$$
\begin{aligned}
V_{i}= & \alpha_{0}+\sum_{j} \alpha_{1 j} \cdot \text { Location }_{i j}+\alpha_{2} \cdot \text { Female }_{i}+\alpha_{3} \cdot \text { Second }_{i} \\
& +\alpha_{4} \cdot \text {. } \text { hicle }_{i}+\alpha_{5} \cdot \text {.ramas }_{i}+\alpha_{6} \cdot \text { Challenge }_{i}+u_{i}
\end{aligned}
$$

where $i$ indexes the incident and $j$ indexes the attributes of location; Model 3 tests the relationship:

$$
\begin{aligned}
V_{i}= & \beta_{0}+\beta_{1} \cdot \text { Civilian }_{i}+\beta_{2} \cdot \text { Female }_{i}+\beta_{3} \cdot \text { Second }_{i} \\
& +\beta_{4} \cdot \text { Hamas }_{i}+\beta_{5} \cdot \text { Challenge }_{i}+u_{i}
\end{aligned}
$$

Table 7 shows the results. These indicate that the outcome of a suicide attack was strongly influenced by the choices of the attacker, but other agents and chance also took a hand. The slope coefficients show the marginal contribution to the number of casualties that arises from the existence of each independent factor, controlling for variation in the others, relative to a base case. All the coefficients have the expected sign, positive or negative. Many are significant, both statistically and in the sense that their size is of practical importance for the numbers of victims. One symptom of multicollinearity in regression output is high R-Squareds combined with low statistical significance of slope coefficients; the results in Table 7 show an opposite pattern and this suggests that multicollinearity has been managed successfully.

The outcome in the base case is shown by the value of the intercept. The base case for Models 1 and 2 is a lone male not associated with Hamas who detonates a personal device in the street without meeting a challenge, and the number of casualties expected in this case is 27 (Model 1) or 30 (Model 2). Some targets yielded much higher casualties than others; the difference between attacking a café and a checkpoint could be 50 or 60 killed and injured. The use of a female attacker or an accomplice would each raise the expected numbers of victims by 30 or 35, and an association with Hamas would raise it by 16 or 20 , even when other factors were held constant.

The intervention of bystanders also made a difference and probably saved 18 casualties on each occasion. This is a smaller figure than the one previously derived from Table 5 for the following reason. Table 5 ("All incidents," col. 6) gave us the average saving, 28 casualties, associated with bystander intervention; this figure is not controlled for other variables. Table 7 (cols 1 and 2) tells us that the marginal saving from bystander intervention was 18 casualties, holding other variables constant. As before, this assumes that the distribution of attacks was independent of the rate of challenge; a larger estimate of the marginal saving would be justified if it could be shown that challenges in low-value locations reduced the number of incidents in highvalue locations. 
Table 7. Factors Influencing the Effects of Suicide Attacks, November 2000 to November 2003

\begin{tabular}{|c|c|c|c|c|c|c|c|c|c|c|}
\hline & (1) & & $(2)$ & & (3) & & (4) & & $(5)$ & \\
\hline Observations & 103 & & 103 & & 103 & & 59 & & 42 & \\
\hline R-Squared & 0.378 & & 0.353 & & 0.370 & & 0.378 & & 0.325 & \\
\hline $\mathrm{F}$ & 4.568 & $* * *$ & 7.416 & $* * *$ & 11.412 & $* * *$ & 8.221 & $* * *$ & 9.386 & $* * *$ \\
\hline \multicolumn{11}{|c|}{ Independent Variables: } \\
\hline Intercept & 27.444 & $* * *$ & 30.801 & $* * *$ & -6.879 & & -2.533 & & 11.575 & \\
\hline Bus & 14.408 & & & & .. & & .. & & .. & \\
\hline Café & 34.228 & $* * *$ & 28.960 & $* * *$ &.. & & .. & & .. & \\
\hline Checkpoint & -24.081 & $* *$ & -27.044 & $* * *$ & .. & & .. & & .. & \\
\hline Offshore & -27.275 & &.. & &.. & & .. & & .. & \\
\hline Residence & -26.444 & &.. & & .. & & .. & & .. & \\
\hline Store & 0.702 & &.. & &.. & & .. & & .. & \\
\hline Travel Stop & 11.041 & &.. & & .. & & .. & & .. & \\
\hline Civilian & & & .. & & 43.731 & $* * *$ & 34.439 & $* * *$ & 50.215 & $* * *$ \\
\hline Female & 35.363 & $* *$ & 34.978 & $* *$ & 39.985 & $* * *$ & 39.839 & $* * *$ & .. & \\
\hline Second & 34.151 & $* *$ & 30.992 & $* *$ & 32.529 & $* *$ & 18.652 & &.. & \\
\hline Vehicle & -14.139 & & -19.461 & $*$ &.. & & .. & &.. & \\
\hline Hamas & 15.963 & $*$ & 19.591 & $* *$ & 21.081 & $* * *$ & .. & &. & \\
\hline Challenge & -18.173 & $* *$ & -17.590 & $* *$ & -14.981 & $*$ & -7.248 & & -31.726 & $* *$ \\
\hline
\end{tabular}

Coverage:

(1), (2), and (3) include full sample.

(4) excludes Hamas observations.

(5) includes Hamas observations only but excludes 2 observations where a second attacker took part.

Key:

* Significant at $10 \%$

** Significant at $5 \%$

*** Significant at $1 \%$. 
These results are robust in that they are present in all the models tested and so can be shown to hold regardless of the exact specification of the remaining characteristics of the attack. Thus Model 1 incorporates detailed information on the location of an attack and the device employed. Some details prove not to be significant. When they are discarded in Model 2, the size and significance of the remaining coefficients is broadly unaffected. In Model 3 the characteristics of location and device are replaced by the characteristics of the target. Again the coefficients on the attacker, faction, and challenge variables prove to be stable and still significant.

The base scenario of Model 3 is a lone male not associated with Hamas who attacks a military target without meeting a challenge. The number of casualties expected in this case is shown by the intercept, which is negative. This is not as it should be and suggests that the model could be misspecified. On the other hand the value of the intercept is small and is not significantly different from zero. ${ }^{22}$ A plausible reading is that a lone male not associated with Hamas who attacked a military target without meeting a challenge tended to succeed only in blowing up himself. The other coefficients are significant, have the expected signs, and have plausible values. In fact the explanatory power of Model 3 measured by its R-Squared is about the same as that of Model 1 but it achieves this level of explanation with fewer independent variables; this makes it more efficient and is reflected in its larger F statistic.

Since higher effectiveness is associated with the use of a female attacker, a second attacker, and the involvement of Hamas, but Hamas used a second attacker on only two occasions and did not use female attackers at all, the marginal contribution of a female attacker or an accomplice in incidents not associated with Hamas may be under- or overstated by regressions that include Hamas-linked incidents. Model 4 repeats the exercise of Model 3 using data from incidents not linked to Hamas. This shows almost no change in the estimated size and significance of the marginal contribution of a female attacker, but the coefficients associated with a second attacker and a challenge become smaller and lose significance. Model 5 repeats the regression using data restricted to Hamas-linked incidents involving a lone attacker. Here we find that the effect of a challenge becomes very significant and quite large, of the order of 30 victims spared. In other words, interventions were highly productive when they were mounted against Hamas operations, which were likely to be more effective than others' in the absence of a challenge. Table 4 showed, however, that Hamas attacks were also less likely to be challenged.

In all the models the R-Squared is between 32 and 38 per cent; this indicates that the greater part of the variation in effectiveness remains unexplained. It is not clear whether the unexplained variation reflects omitted variables that could potentially be measured and taken into account, or influences that were intrinsically random and cannot be controlled.

\section{Conclusions}

We began by noting that the outcomes of the four suicide hijackings on 9/11 appeared to vary with the character of interaction between the terrorists and their captors. The present study of 103 suicide operations in Israel suggests that this was not accidental. The outcomes of suicide attacks depended on many factors ranging from the location of the attack to the qualities of the attacker and the identity of the faction that organized it. Controlling for these, 
the interaction between bombers and bystanders also influenced the numbers of victims arising. Military personnel at checkpoints, security guards in shopping malls and cafés, and civilian commuters and shoppers could all play a role. The number of victims spared death or injury when bystanders intervened, taking other variables as given, was 18 per incident across the whole dataset and more than 30 per incident if we consider only Hamas operations.

These findings confirm that some of the patterns found from the study of natural and technological disasters may also be found in terrorist emergencies. Citizens under attack are not inevitably reduced to passivity or helplessness; even in largely unanticipated "flash" emergencies that demand instant response they are likely to display varying degrees of altruistic or communityoriented behaviour.

There are immediate implications for the design of security policy. A society under attack by suicide terrorists can protect itself by active security measures, and these should not be limited to before and after the event. In the case of Israel it is clear that the readiness of citizens to take action against suicide operations that were actually in progress had a considerable effect in protecting potential victims and limiting casualties. Some casualties were inevitable, however, and those who took action were usually the first to suffer.

These conclusions should be considered preliminary. One obstacle to further progress is the effort required to establish more comprehensive datasets on suicide operations that can be analysed numerically. The present analysis of a relatively narrow dataset suggests that more systematic data collection would pay substantial dividends. More data on the personal qualities of the suicide operatives and on the counter-measures locally in place at the time of each incident could be especially informative.

The qualities and actions of the bystanders who die to save others also merit closer examination. If it is of interest to study why some die so as to kill, it may also repay study to find out why some die in order to save life. More detailed investigation of the different contexts and consequences of citizen response would also be useful. It may appear from the present study that citizens suspecting a suicide attack should be advised to have a go in the hope of saving the lives of others, but expect to die themselves. Whether doing anything is always better than doing nothing, however, will emerge more clearly when it is possible to carry out statistical comparisons of the consequences of different actions in different contexts.

Finally, a more general qualification is in order. Vigilance is costly, and the data do not give us any indication of whether Israel achieved the right level of watchfulness against suicide attacks given its price. The main cost of vigilance is probably indirect: that of transforming a relatively open, trusting society into a more closed community, suspicious of differences in facial appearance, dress, and manner, and permanently on guard against strangers. This also merits scholarly evaluation. 


\section{Notes}

${ }^{1}$ Robert A. Pape, “The Strategic Logic of Suicide Terrorism," American Political Science Review, 97:3 (2003), p. 346.

${ }^{2}$ Ronald W. Perry and Michael K. Lindell, "Understanding Citizen Response to Disasters with Implications for Terrorism," Journal of Contingencies and Crisis Management, 11:2 (2003), p. 54; The 9/11 Commission Report, Final Report of the National Commission on Terrorist Attacks upon the United States (Washington, DC: U.S.GPO, 2004), pp. 13-14.

${ }^{3}$ Organizations: Ethan Bueno de Mesquita, "The Quality of Terror," forthcoming in American Political Science Review, 49:3 (2005); Bruce Hoffman and Gordon H. McCormick, "Terrorism, Signalling, and Terrorist Attack," Studies in Conflict and Terrorism, 27 (2004), pp. 243-281; Andrew Kydd and Barbara F. Walter, "Sabotaging the Peace: The Politics of Extremist Violence," International Organization, 56:2 (2002), pp. 263-296; Assaf Moghadam, "Palestinian Suicide Terrorism in the Second Intifada: Motivations and Organizational Aspects," Studies in Conflict and Terrorism, 26 (2003), pp. 65-92; Brigitte L. Nacos, "The Terrorist Calculus Behind 9/11: A Model for Future Terrorism?" Studies in Conflict and Terrorism, 26 (2003), pp. 1-16; Pape, "Strategic Logic"; Todd Sandler and Daniel G. Arce M., "Terrorism \& Game Theory," Simulation and Gaming, 34:3 (2003), pp. 319337. Persons: Mark Harrison, "An Economist Looks at Suicide Terrorism," forthcoming in Christopher Ankersen, ed., Terrorism: Challenge for the 21st Century? Understandings and Responses (London: Polity Press, 2005); Alan B. Krueger and Jitka Malecková, "Education, Poverty and Terrorism: Is There a Causal Connection?" Journal of Economic Perspectives, 17:4 (2003), pp. 119-44; Ariel Merari, "The Readiness to Kill and Die: Suicidal Terrorism in the Middle East," in Walter Reich, ed., Origins of Terrorism: Psychologies, Ideologies, Theologies, States of Mind (second edition, Washington, DC: Woodrow Wilson Center and Johns Hopkins University Press, 1998), pp. 192207; Quintan Wiktorowicz, "Suicide Bombings: Do Beliefs Matter?" (Memphis, TN: Rhodes College, working paper, 2004): internet address: www.rhodes.edu.

${ }^{4}$ Disaster Prevention and Mitigation: a Compendium of Current Knowledge, vol. 12: Social and Sociological Aspects (New York: United Nations, Office of the United Nations Disaster Relief Coordinator, 1986); E.L. Quarantelli, "How Individuals and Groups React During Disasters: Planning and Managing Implications for EMS Delivery" (University of Delaware, Disaster Research Center, Preliminary Paper no. 138, 1989): internet address www.udel.edu/DRC.

${ }^{5}$ Allen H. Barton, Communities in Disaster: A Sociological Analysis of Collective Stress Situations (Garden City, NY: Doubleday, 1969); Russell R. Dynes, "Situational Altruism: Toward an Explanation of Pathologies in 
Disaster Assistance" (University of Delaware, Disaster Research Center, Preliminary Paper no. 201, 1994). ): internet address www.udel.edu/DRC.

${ }^{6}$ Ronald W. Perry and Michael K. Lindell, "Understanding Citizen Response to Disasters with Implications for Terrorism," Journal of Contingencies and Crisis Management, 11:2 (2003), pp. 49-60; Ira Helsloot and Arnout Ruitenberg, "Citizen Response to Disasters: a Survey of Literature and Some Practical Implications," Journal of Contingencies and Crisis Management, 12:3 (2004), pp. 98-111.

${ }^{7}$ Moghadam, "Palestinian Suicide Terrorism"; see also a number of working presentations made available online by terrorismexperts.org.

${ }^{8}$ Arie Perliger, and Ami Pedahzur, "Counter-Terrorism: Factors Influencing Effectiveness" (working presentation, no date): internet address www.terrorismexperts.org.

9 “Strategic Logic,” p. 351.

${ }^{10}$ Incidents and Casualties Database (Herzlia, Israel: International Policy Institute for Counter-Terrorism): internet address www.ict.org.il.

${ }^{11}$ A database reliant on press reports is vulnerable to selection bias and also measurement error both at the stage of original reporting and at the stage of compilation. Selection bias, for example the omission of many low-value or zero-value incidents, is the more dangerous of the two. Below I discuss the under-recording of suicide attacks that were intercepted or disrupted before execution, and I also consider the scope for under-recording of bystander interventions in high-value incidents when all the witnesses might have been killed. Measurement errors that are not systematic normally make it harder for the investigator to draw significant conclusions but should not bias them otherwise. I have adjusted the records themselves in two details (1) the double incident of 18 May 2003 is coded as two separate events because, although coordinated from a distance, they took place in different locations (2) the attacker of 19 May 2003 is coded female rather than male on the basis of an independent press report: Sa'id Ghazali, "The Story of Hiba, 19, a Suicide Bomber. Can the Road-Map Put an End to All This?" The Independent (London, 27 May 2003).

${ }^{12}$ The numerically coded dataset is available for inspection in the form of a Microsoft Excel spreadsheet and may be downloaded from [internet address to be added].

13 “Israel and Palestine: Who's Winning the Fight?" The Economist (London, July 3 2004), p. 61.

${ }^{14}$ Pape, "Strategic Logic."

15 "Fence is Proving Effective," (Israel, Ministry of Defence, 10 December 2003): internet address: www.securityfence.mod.gov.il. 
${ }^{16}$ Moghadam, "Palestinian Suicide Terrorism."

${ }^{17}$ Bueno de Mesquita, "Quality of Terror."

${ }^{18}$ Bivariate regressions of the numbers of casualties per incident on time, run separately for each faction, and a pooled multiple regression of casualties per incident on faction dummies and the faction-specific serial number of the incident, not reported here, yield slope coefficients not significantly different from zero, even when other variables are included such as whether or not the operation was disrupted by a challenge.

${ }^{19}$ According to Merari, "Readiness to Kill," Hezbollah established the basic procedures for organising suicide attacks in Lebanon in the 1980s

20 "Rational Martyrs vs Hard Targets: Evidence on the Tactical Use of Suicide Attacks" (UCSD and Stanford University, working paper, 2003): internet address econ.ucsd.edu/ elberman.

${ }^{21}$ Of all the incident variables reported in the dataset, bystander intervention seems most liable to mismeasurement. Potential witnesses may be killed, injured, or shocked. This should not bias statistical results as long as measurement error is uncorrelated with the scale of death and injury. If there were several high-casualty incidents in which a challenge went unreported because all the bystanding witnesses were killed or for some other reason unable to recall it, then our estimate of the productivity of a challenge might be inflated as a result.

${ }^{22}$ An ordered probit model would avoid this bias. In the present case the potential bias appears small and the gains associated with the relative transparency of an ordinary least squares regression seem large. 